\title{
A METHOD OF CORRECTING METATARSUS PRIMUS VARUS
}

\section{Preliminary Report}

\author{
V. H. Ellis, London, ENgland
}

Hallux valgus and its complications are responsible for a great amount of pain and disability. The precursor of hallux valgus in many cases is a varus deformity of the first metatarsal. The deformity is common in girls and is often hereditary. Several operations have been devised for the correction of metatarsus primus varus, most of them involving some form of osteotomy. These procedures are unsatisfactory for several reasons: 1) the operation is usually carried out on a symptomless foot; 2) it requires a major operation and plaster fixation causing prolonged incapacity; 3) the immediate correction is not always satisfactory ; 4) the deformity may recur and some stiffness of the foot may persist; 5) parents are often reluctant to allow such operations on children in the absence of symptoms. If it were possible to correct this deformity effectively by a minor operation involving minimal disability and without impairing mobility of the foot or patient, it would be of much wider use.

Prevention of growth on the lateral side of the basal epiphysial disc of the first metatarsal produces a slow correction of the deformity during growth. An attempt has been made to achieve this by the use of small staples, after the manner of Blount and Clarke (1949).

\section{APPLIED ANATOMY}

Girls' feet continue to grow in length until the age of fifteen years; boys until seventeen years (Meredith 1944). The curve of average growth in foot length (Fig. 1) is derived from

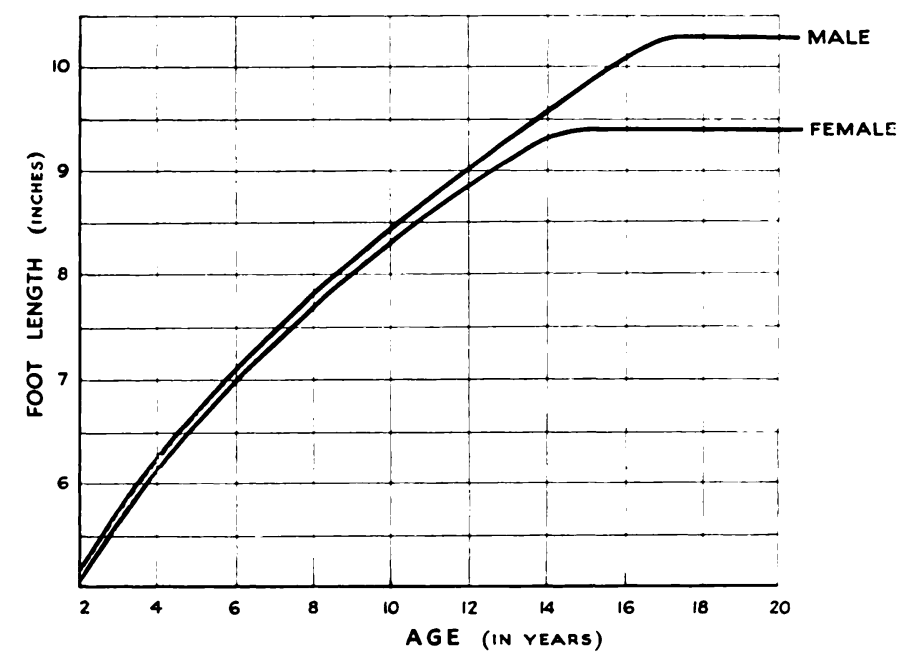

FIG. 1

Graph showing average growth in foot length. (By courtesy of the British Boot, Shoe and Allied Trades Research Association.)

a survey of 1,882 girls and 1,836 boys of various ages from various parts of England.* It will be seen that in girls between twelve and fifteen years the average increase in foot length is half an inch, and between ten and fifteen years over one inch. If it is assumed that growth of the first metatarsal is not less than a quarter of this total, a correction of the order of

* The British Boot, Shoe and Allied Trades Research Association, Research Report Number R.R. 114. 
15 degrees could be attained by unilateral arrest of growth at the age of ten years. It appears that unilateral epiphysial arrest at the age of twelve years will produce significant correction in average cases in girls.

\section{TECHNIQUE OF OPERATION}

Lnder a tourniquet the lateral side of the epiphysial plate at the base of the first metatarsal is exposed by a vertical incision one and a quarter inches long on the lateral side of the tendon of extensor hallucis longus. The periosteum is dissected off the metaphysis and epiphysis, which here shows a quarter of an inch of cancellous bone. A small elevator is passed round the bone and depressed, keeping the dorsalis pedis artery out of harm's way and depressing the second metatarsal as far as possible to expose the lateral aspect of the first metatarsal; insertion of a staple on the dorsum might produce a metatarsus elevatus deformity. Three, or at least two, stainless steel wire staples are inserted and driven home, making sure that they bridge the cartilage plate and do not impinge on the tarso-metatarsal joint. Only skin sutures are required for closure.

A few day's' stay in hospital is all that is required and after the sutures have been removed no further treatment is necessary. Estimation of deformity and degree of correction is obtained from standard radiographs before operation and at three-monthly intervals afterwards.

\section{TECHNIQUE OF RADIOGRAPHY AND MEASUREMENT OF METATARSAL ANGLE}

The patient is seated on the X-ray table and the feet are placed side by side on the film, separated by about half an inch; the knees should touch and the lower legs should be vertical

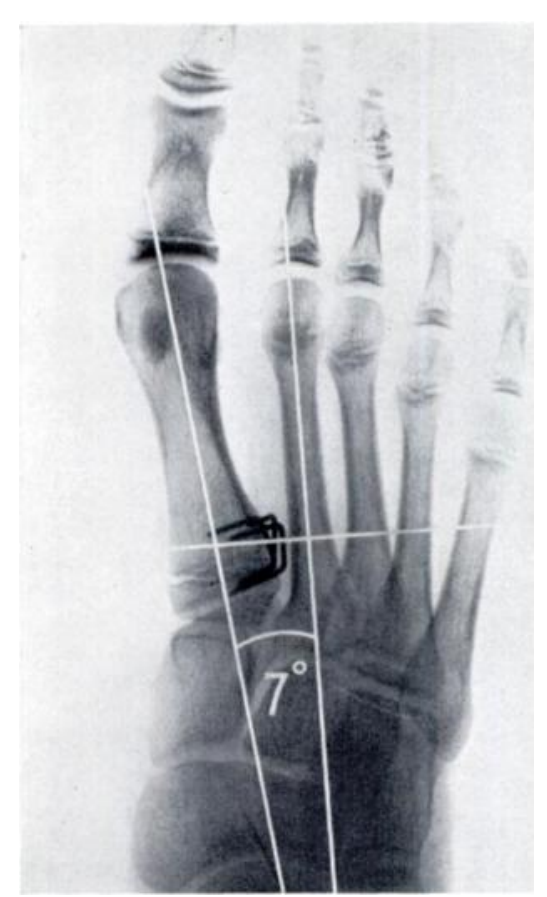

FIG. 2

Radiograph showing staples in position and method of measurement of metatarsal angle. above the ankle joints. The $\mathrm{X}$-ray tube is angled by 15 degrees towards the ankle and the central ray is directed to a point between the navicular-cuboid intervals of both feet. The film should be sufficiently penetrated to reveal adequately the lateral margin of the base of the second metatarsals. When this constant technique is used subsequent angular measurements should give comparable results.

Measurement-The widest transverse dimensions of the heads of the first and second metatarsals are measured and a bisecting point is made on the film. In cases where the epiphysis for the head of the second metatarsal is insufficiently developed to cap the metaphysis, the measurement is made across the metaphysis. Similar bisecting points are made across the base of the second metatarsals and the metaphyses of the first metatarsals. The points on each side are then joined by lines which are produced in the direction of the heel. A square protractor is then used to erect a right angle on the second metatarsal line (Fig. 2). This same protractor is then used to measure the angle made by the erected right angle with the first metatarsal line. The square protractor allows the angle to be measured on each side in order to give greater accuracy. With this technique it should be possible for the angular measurements to be accurate to within 1 degree. 


\section{RESULTS}

The operation has been performed on twenty feet in this series. All the patients were girls ranging in age from five and three-quarters to twelve and a half years. The prime metatarsal angle varied from 7 to $12 \cdot 5$ degrees, compared with a control group average of $5 \cdot 7$ degrees.

The longest follow-up was fourteen months, the shortest three months. In this time five cases showed improvement, one was worse and the rest showed no change of angle. The greatest decrease in angle was $\mathbf{5} \cdot \mathbf{5}$ degrees. In one case the foot not operated upon showed a diminution of angle of $1 \cdot 5$ degrees, compared with a diminution of $\mathbf{3}$ degrees in the foot subjected to operation.

Comment-This preliminary report suggests that the deformity of metatarsus primus varus may be correctable by a minor operation to produce unilateral growth arrest of the first metatarsal.

I would like to express my thanks to Dr Ronald Murrav, Radiologist to the Lord Mayor Treloar's Hospital, Alton, for his description of the radiographic technique and method of measurement, and for his careful evaluation of the results.

\section{REFERENCES}

Blount, W. P., and Clarke, G. R. (1949): Control of Bone Growth by Epiphyseal Stapling. Journal of Bone and Joint Surgery, 31-A, 464.

The British Boot, Shoe and Allied Trades Research Association Research Report. No. R.R. 114.

Meredith, H. V. (1944): Human Foot Length from Embryo to Adult. Human Biology, 16, 207. 